\title{
Variation of Atmospheric Temperature with Height in the Phenomena of Lightning Waveforms
}

\author{
Pitri Bhakta Adhikari \\ Department of Physics, Tri-chandra Multiple Campus, Tribhuvan University, Kathmandu, Nepal
}

Email address:

pitribhakta_adhikari@hotmail.com,pbadhikari09@gmail.com

\section{To cite this article:}

Pitri Bhakta Adhikari. Variation of Atmospheric Temperature with Height in the Phenomena of Lightning Waveforms. World Journal of Applied Physics. Vol. 4, No. 4, 2019, pp. 46-50. doi: 10.11648/j.wjap.20190404.11

Received: October 8, 2019; Accepted: October 9, 2019; Published: December 10, 2019

\begin{abstract}
The temperature at different height at different places is different, it may depend on various factors. The variation of atmospheric temperature varies as a function of height taken from the sea level. The temperature decreases with height in the troposphere. The location of the charge centre appears to be determined by temperature and not by the height of the cloud above the ground. The main negative charge centre is generally located between the $-10^{\circ} \mathrm{C}$ and $-25^{\circ} \mathrm{C}$ isotherms with the main positive charges some km higher up. Due to the variation of temperature, the ice crystal, super cooled water droplet etc. move updraft and downdraft, forms the charge in the cloud due to which the lightning phenomena occurs. In the cloud, the negative charge lies in the central part of the cloud, positive charge remains on above the negative charge centre in the cloud and small amount of positive charge as a pocket charge remains on the bottom part of the cloud. The positive ground flashes are initiated from the upper positive charge region and the negative ground flashes are initiated from the negative charge region in the thunder-cloud. The lower positive charge also play an important role for determining the different types of lightning.
\end{abstract}

Keywords: Temperature and Height, Negative Charge Centre, Positive Charge Centre, Positive Lightning, Negative Lightning

\section{Introduction}

In the summer season, the sunlight provides sufficient amount of heat and warms the ground and also the water surface. The ground warms the air in contact with it. The air after heated expands and becomes lighter than the surrounding. As it goes up, the atmospheric pressure decreases and it expands further. In the mean-time, the temperature decreases and the ability of air to hold moisture (humidity) decreases. So the moisture in the air condenses and form water drops. Hence, the thunderstorm cloud or cumulonimbus develops in the atmosphere from the water droplet and vapor is produced from the surface of the earth. [1]

These water drops freeze and form tiny ice crystals, snow crystals etc. in the cloud and still remain as water drops even below $0^{\circ}$ Celsius temperature. They are called super cooled water droplets. As the height of the cloud increases, the water vapor changes in different phases and forms snow crystals, ice crystals, graupel particle, super cooled water droplets etc. Again the tiny ice particles, snow crystals, ice crystals, collides with super cooled water droplets and the size increases which is called graupel particle. As the size of the graupel particles increases, they become heavier and start to fall. As the temperature difference is high between the two layers of the cloud, they move fast. Due to the random motion of graupel particles, snow crystals, ice crystals, water molecules in the cloud, the electrification phenomena occurs by the process of friction. They produce large amount of charge in the cloud. The simplest diagram of the charge structure of thunderstorm is the tripole standard model which contains the main negative charge at the centre of the cloud, main positive charge centre above the negative charge and a lower positive charge as a pocket charge on the bottom part of the cloud. [2] The main charging area in a thunderstorm occurs in the central part of the storm where air is moving upward rapidly (updraft) and the main negative charge centre is found in a relatively narrow temperature range from -10 to -25 degree Celsius, regardless of the height of the ground below this storm in which the cloud contains the super cooled water droplet, ice crystal etc. [1,3] These ingredients, super cooled water droplet and ice crystal play important roles for 
the so called non inductive charging mechanism of the position of negative and positive charges to operate. [4] At that place, the combination of temperature and rapid upward air movement produces a mixture of super-cooled water droplets (small water droplets below freezing), small ice crystals, and soft hail (graupel). The updraft carries the super-cooled water droplets and very small ice crystals upward. At the same time, the graupel, which is considerably larger and denser, tends to fall or be suspended in the rising air. The differences in the movement of the precipitation cause collisions to occur. The updraft carries the positively charged ice crystals upward toward the top of the storm cloud. The larger and denser graupel with negatively is either suspended in the middle of the thunderstorm cloud or falls toward the lower part of the storm. [2, 5] The examples of different places at various heights having different temperatures are given in table 1. From these examples of table 1, the structure of the cloud is generalized that the negative charge centre lies in the central part of the cloud in the range of temperature $-10^{\circ} \mathrm{C}$ to $-25^{\circ} \mathrm{C}$, main positive charge centre lies above the negative charge centre and below the temperature $-25^{\circ} \mathrm{C}$ and small positive charge pocket remains on the bottom part of the cloud. [5-7] The variation in temperature as a function of height of atmosphere is shown in figure 1 and the structure of the cloud is shown in figure 2 .

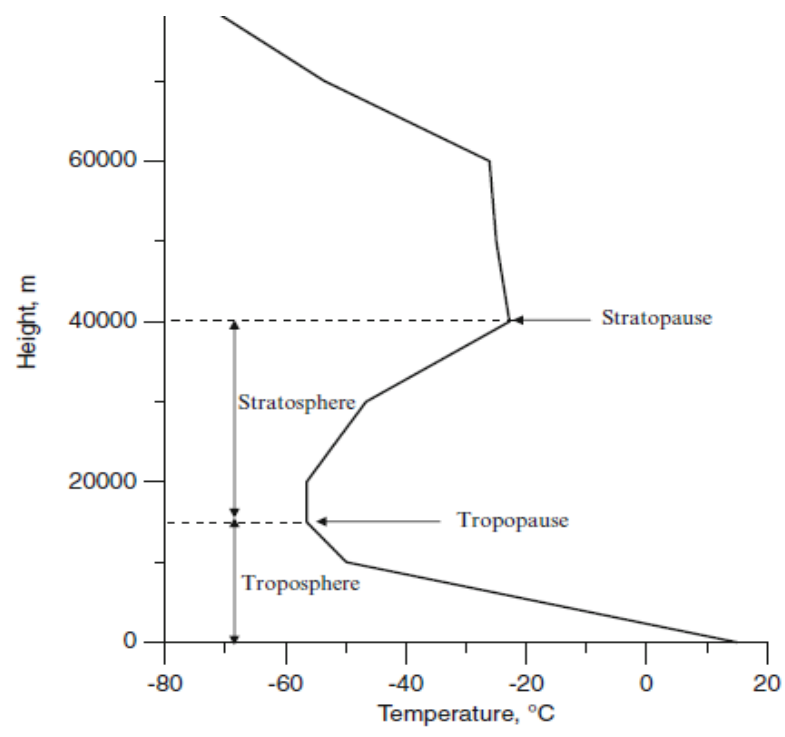

Figure 1. Variation in temperature as a function of height of atmosphere.

Table 1. The example of different places at various heights having different temperatures.

\begin{tabular}{|c|c|c|c|c|}
\hline Researcher & Places & Heights a & & Temperatures \\
\hline \multirow{6}{*}{ Krehbiel et al. [7] } & \multirow{2}{*}{ Florida } & $6-8$ & Negative & $-10^{\circ} \mathrm{C}$ to $-25^{\circ} \mathrm{C}$ \\
\hline & & $8-15$ & Positive & Above $-40^{\circ} \mathrm{C}$ \\
\hline & \multirow{2}{*}{ New Mexico } & $6-8$ & Negative & $-10^{\circ} \mathrm{C}$ to $-25^{\circ} \mathrm{C}$ \\
\hline & & $8-15$ & Positive & Above $-40^{\circ} \mathrm{C}$ \\
\hline & \multirow{2}{*}{ Japan } & $2-8$ & Negative & $-10^{\circ} \mathrm{C}$ to $-25^{\circ} \mathrm{C}$ \\
\hline & & $8-15$ & Positive & Above $-35^{\circ} \mathrm{C}$ \\
\hline \multirow{2}{*}{ Simpson and Robinson [8] } & \multirow{2}{*}{ England } & $6-15$ & Positive & Above $-40^{\circ} \mathrm{C}$ \\
\hline & & $1.5-3$ & Positive & 0 to $\left(-5^{\circ} \mathrm{C}\right)$ \\
\hline \multirow{2}{*}{ Winn et al. [9] } & \multirow{2}{*}{ New Mexico } & $4.8-5.8$ & Negative & $-10^{\circ} \mathrm{C}$ to $-25^{\circ} \mathrm{C}$ \\
\hline & & Above 10 & Positive & Above $-40^{\circ} \mathrm{C}$ \\
\hline Marshall and Winn [10] & Japan & $1-3$ & Negative & 0 to $\left(-10^{\circ} \mathrm{C}\right)$ \\
\hline \multirow{2}{*}{ Weber et al. [11] } & \multirow{2}{*}{ New Mexico } & $5.5-8$ & Negative & -5 to $\left(-20^{\circ} \mathrm{C}\right)$ \\
\hline & & Above 8 & Positive & Below $\left(-25^{\circ} \mathrm{C}\right)$ \\
\hline
\end{tabular}

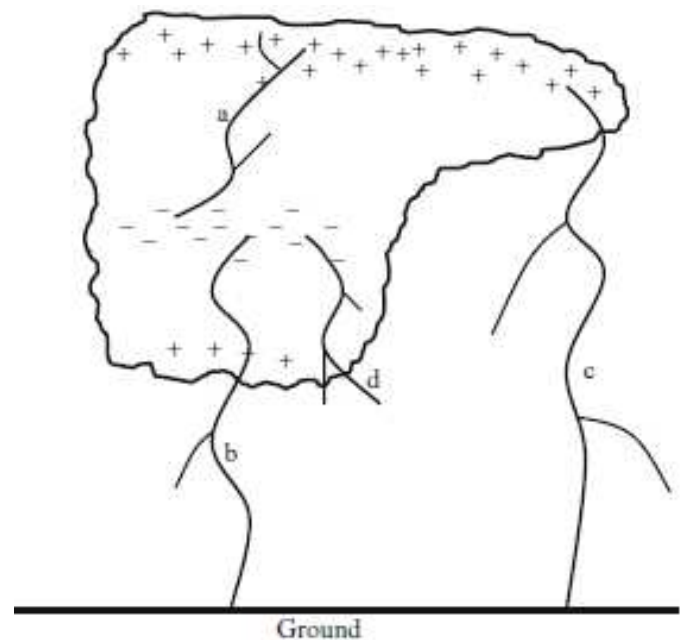

Figure 2. The tripole structure of the cloud, a represents intracloud lightning, $b$ represents negative Cloud to ground lightning, $c$ represents positive Cloud to ground lightning and d represents Cloud to air discharge.
The upper region of the atmosphere attains positive charge and lower region of the atmosphere attains negative charge then they produce electric field. If the amount of charge increases, then the electric field also increases. If the electric field is sufficient for electric break-down of air, then discharging phenomena occurs. This discharging phenomena is called lightning. Hence, the lightning is the electrical discharging phenomenon which is common natural activity in the atmosphere. On the process of lightning, huge energy is released in different form such as light, heat, sound, etc. They produce several electromagnetic radiations of different frequency from DC to the order of GHz. So it is an extremely complex electrical discharge. Although, there is a large number of research addressing numerous aspects of lightning, a complete theory of the flash does not exist. [12]

\section{Literature Review}

Lightning can cause severe damages to physical structures, 
human life, etc. Transmission lines, transmission towers, communication towers, and other tall physical structures are more vulnerable to the lightning activities. More than two hundred sixty years ago, the pioneer of research in lightning, Benjamin Franklin gave the idea that lightning is an electrical discharge in nature. Since then, many great advances on our knowledge of lightning phenomena have taken place, and then some significant work has been carried out in some last decades. Mostly the lightning activities are categorized into two parts, cloud discharges and ground discharges. The cloud discharges include cloud to cloud, cloud to air, inter-cloud, intra-cloud lightning whereas the ground discharges are only related to ground, so called ground-lightning $[1,2,5,12]$

Cloud Discharges: If the discharges happen inside a thundercloud or between the thunder clouds, it is called cloud discharge. As compared to the cloud to ground discharges, very few studies have been carried out on cloud discharges. There are several reasons for the lack of investigations on cloud flashes such as difficulty in taking measurements, less vulnerability of man-made structure and human life at ground level, less intense and less visible etc. Despite the low number of studies on cloud flashes, this study is very important for the aviation industry, communication systems, etc.

Ground discharges: When lightning strikes the grounded object, it is called ground discharges. According to Berger, the ground discharges are categorized by cloud to ground lightning in terms of direction of motion, upward or downward, and the sign of charge positive or negative of the leader that initiates the discharge. According to Berger there are: Upward negative lightning; Upward positive lightning; Downward negative lightning and Downward positive lightning. [1, 5, 13, 14] According to the Berger, the downward negative lightning transports negative charges from the main negative charge centre to ground and accounts for $90 \%$ of ground flashes. [13] Less than the $10 \%$ of ground flashes are downward positive lightning which transports positive charges to ground from the main positive charge centre. The remaining two upward lightning are very rare, as opposed to the downward lightning, which occur due to the presence of tall structural objects of height more than one hundred and fifty meters. In the tripole structure of the cloud shown in figure 2 , 'a' represents intra-cloud lightning, ' $b$ ' represents negative cloud to ground lightning, 'c' represents positive cloud to ground lightning and 'd' represents cloud to air discharge. Examples of electric field waveform of normal negative return strokes in cloud-to-ground lightning flashes is shown in figure 3 and positive return strokes in cloud-toground lightning flashes is shown in figure 4.

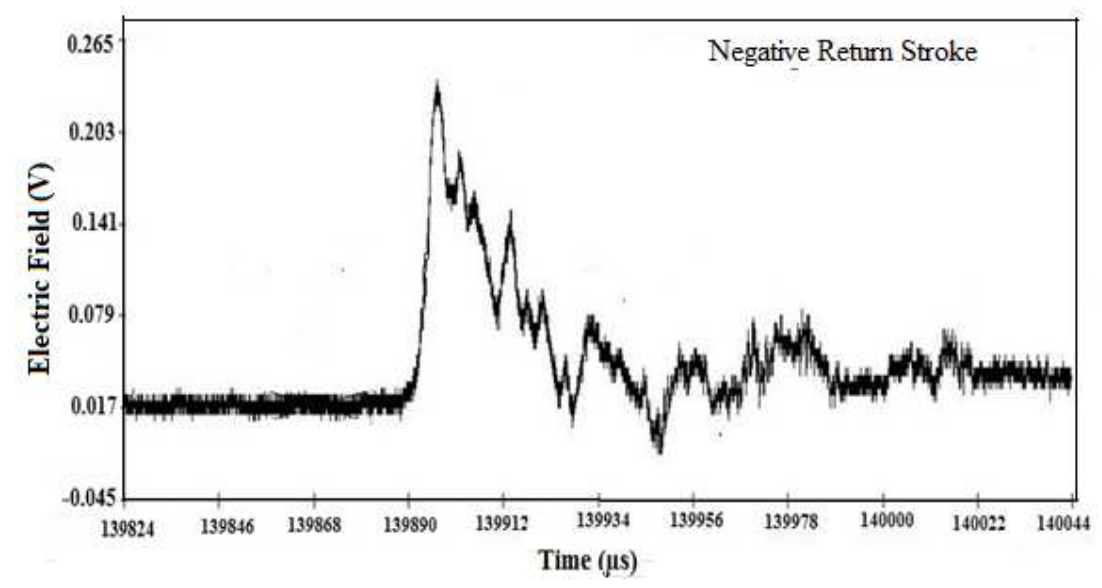

Figure 3. Examples of electric field waveform of normal negative return strokes in cloud-to-ground lightning flashes shown on a 220 $\mu$ s time scale. [15].

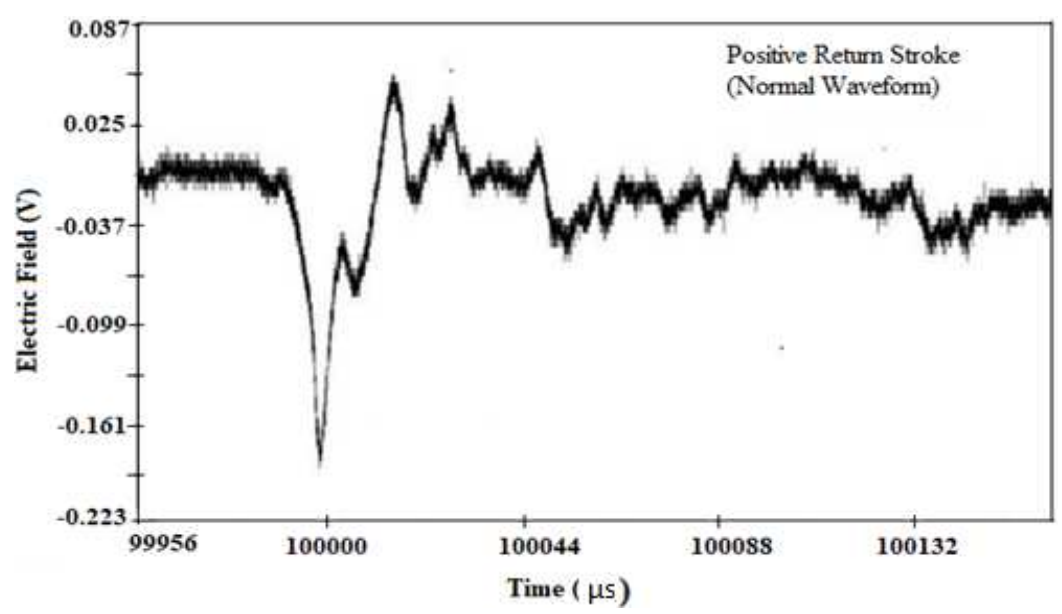

Figure 4. Examples of electric field waveform of normal positive return stroke on cloud-to-ground lightning flashes shown on a 220 $\mu$ s time scale. [15]. 


\section{Measurements of Lightning}

Lightning has been investigated by using different measurements. According to Uman, some of the processes of measurement are spectroscopic measurement; electric current measurement; photographic method; electric and magnetic field measurement; acoustic measurement and a combination of two or more than two of these measurements. [2]

According to Uman, the development in the understanding of lightning was initiated by the use of lightning photography on a moving film or plate by Hoffert in 1889 in England. [2] Pockels in 1897 began the development of magnetic links by measuring the amplitudes of lightning current. [2, 12, 13] Berger; Rakov and Uman etc. further explained that a third branch of research was concerned with the measurement of electric fields, the first result being reported by Wilson in 1916. [1, 12] Berger; Nanevicz et al. described that various motivations for studying the electrical properties of lightning existed and the complexity of the flash has continued to challenge the creativity of lightning experimenters and instrument designers to this date. $[12,16,17]$

Sign-convention: In the atmospheric sign convention, a downward directed electric field is considered positive and upward directed electric field is considered negative. A positive field is defined in terms of a negative charge being lowered to ground or positive charge being raised. According to this definition, a lightning flash that transports negative charge to ground gives rise to a positive electric field change. Similarly, a lightning flash that transports positive charge to ground gives rise to a negative electric field change. [18]

\section{Results and Discussions}

The composition of water droplet and ice crystals forms clouds in the earth's atmosphere, which are commonly white in appearance. The cloud appears white because these liquid and solid particles have high wavelength relative to visible light. Air becomes super-saturated with water vapor, then, the super-saturated air is lifted up and cooled by adiabatic expansion. The lifted process is caused by heating of the air near the earth's surface and also it is heated by sunlight directly. The warmed air is lifted up at a height at which the super saturation condition is achieved. When the air is lifted up at $1000 \mathrm{~m}$ from the earth's surface, the temperature of this air becomes around $0^{\circ} \mathrm{C}$. Higher the air, lower is the temperature than $0^{\circ} \mathrm{C}$. At about $10000 \mathrm{~m}$ above the earth's surface, the temperature reaches about $-34^{\circ} \mathrm{C}$ or even less than that. The temperature at different height at different places should be different, it may depend on various factors. The temperature measured of the atmosphere from aeroplane can be taken as an example which is given in table 2 .

Table 2. The temperature measured in the atmosphere.

\begin{tabular}{lll}
\hline S. $\mathbf{N}$. & Height from earth's surface $(\mathbf{m})$ & Temperature $\left({ }^{\circ} \mathbf{C}\right)$ \\
\hline 1. & 1000 & 0 \\
2. & 5680 & -8 \\
3. & 7962 & -24 \\
\hline
\end{tabular}

\begin{tabular}{lll}
\hline S. N. & Height from earth's surface $(\mathbf{m})$ & Temperature $\left({ }^{\circ} \mathbf{C}\right)$ \\
\hline 4. & 8758 & -27 \\
5. & 9331 & -29 \\
6. & 9755 & -33 \\
7. & 10058 & -34 \\
8 & 10475 & -45 \\
9 & 10752 & -52 \\
10 & 10980 & -62 \\
11 & 11281 & -65 \\
12 & 11581 & -46 \\
\hline
\end{tabular}

From this table, we can say that if the height of the air is uplifted, the temperature of the air decreases.

Mechanism: Thundercloud generally contains two main charge centres, positive charge at the top of the cloud and the negative charge just below the positive charge and a small pocket of positive charge located at the base of the cloud. The location of the charge centre appears to be determined by temperature and not by the height of the cloud above the ground. The main negative charge centre lies within the temperature between the $-10^{\circ} \mathrm{C}$ and $-25^{\circ} \mathrm{C}$ and the main positive charge centre lies some $\mathrm{km}$ above the negative charge. The main positive charge centre lies at very low temperature lower than $-25^{\circ} \mathrm{C}$. There is a small pocket of positive charge below the main negative charge centre, close to the freezing level, that appears to be associated with the precipitation shaft.

If charge transfers to the ground from the cloud, then ground flash occurs. The ground flash brings the positive charge from cloud to earth, which is called positive ground flash and the flash that brings negative charge from cloud to earth is called negative ground flash. Again on increasing the number of charges, the electric field also increases and the maximum electric field just before breaking the molecules is called dielectric strength of the medium. If the electric field is greater than $30 \mathrm{KV} / \mathrm{cm}$, then the air (initially insulator) becomes conductor and there is electric breakdown of the air. A ground flash is initiated by an electrical breakdown process in the cloud called preliminary breakdown. This process leads to the creation of a column of charge called the stepped leader that travels from cloud to ground in a stepped manner.

Comparison: On comparing this result with others, such as Weber et al., Winn et al.; Marshall and Winn; Krehbiel et al. etc., the temperature at the height of five kilometers to eight kilometers are in the range of $-10^{\circ} \mathrm{C}$ to $-25^{\circ} \mathrm{C}$. In this region, negative charge centre resides and above that region on the upper atmosphere there is positive charge centre.

\section{Conclusion}

The phenomenon of lightning discharge has not been fully understood even though so many measurements and experiments have been conducted for natural lightning. Much of the success that has been achieved in understanding the lightning phenomena is due to the optical measurements and electromagnetic field measurements. Positive ground flashes are of much interest for the lightning community because of 
its association with the upper atmospheric discharges (such as sprites) and the magnitude of current possessed by them. The positive ground flashes are probably initiated from the upper positive charge region and the negative ground flashes are initiated from the negative charge region in the thundercloud. The location of the charge Centre appears to be determined by temperature and not by the height of the cloud above the ground.

\section{References}

[1] Rakov, V. A., \& Uman, M. A. (2003). Lightning: Physics and Effects. Cambridge University Press, UK.

[2] Uman, M. A. (2001). The Lightning Discharge. Dover Edition, New York.

[3] Krehbiel, P. R., Brook, M., McCrory, R. A., (1979). An analysis of the charge structure of lightning discharge to ground. Journal of Geophysical Research, Vol. 84.

[4] MacGorman, D. R., \& Rust, W. D. (1998). The Electrical Nature of Storms. New York: Oxford Univeristy Press.

[5] Cooray, V. (2015). An Introduction to Lightning. Springer Netherlands.

[6] Krehbiel P. R., (1986). The electrical structure of thunderstorm, the earth's electrical environment. National Academy Press, Washington D. C.

[7] Krehbiel, P. R., Brook, M., Lhermitte, R. L. and Lenon, C. L. (1983). Lightning charge structure in Thunderstorm. In "proceedings in Atmospheric Electricity", Deepak Hampton, Virginia.

[8] Simpson, G. C. and Robinson, G. D. (1941). The distribution of electricity in the thunderclouds, proceedings in Research Society, London series A, Vol. 117.
[9] Winn, W. P., Moore, C. B. and Holmes, C. R. (1981). Electric Field Structure in an Active Part of a small, Isolated Thundercloud. Journal of Geophysical Research, Vol. 86.

[10] Marshall, T. C., Winn, W. P. (1985). Comments on "The 'Rain Gush,' Lightning, and the lower positive centre in thunderstorm" by E. R. Jayaratne and C. P. R. Saunders. Journal of Geophysical Research.

[11] Weber, M. E., Christian, H., J., Few, A. A. and Stewart (1982). A thundercloud Electric field sounding, Charge Distribution and Lightning. Journal of Geophysical Research, Vol. 87.

[12] Sharma, S. (2007). Electromagnetic Fields Radiated by Lightning in Tropical and Temperate Regions. PhD thesis. Faculty of Science, University of Colombo, Sri Lanka.

[13] Berger, K. (1977). The Earth Flash. In Lightning, Physics of Lightning. Academic Press, New York.

[14] Uman, M. A. (1987). Lightning. Dover Publications, New York.

[15] Adhikari, P. B., Sharma, S. R., Baral, K. N., \& Rakov V. A. (2017). Unusual lightning electric field waveforms observed in Kathmandu, Nepal, and Uppsala, Sweden (2017); Journal of Atmospheric and Solar-Terrestrial Physics, 164, 172-184. Homepage: www.elsevier.com/locate/jastp

[16] Nanevicz, J. E., Vance, E. F., \& Hamm, J. M. (1987). Observation of lightning in the frequency and time domains. Lightning Electromagnetics, 7, 267-286.

[17] Adhikari, P. B., (2019), Measurement of Electric Fields due to Lightning Radiation. Springer Nature Switzerland $A G$, doi.org/10.1007/978-3-030-14680-1_5, AISC 905 pp. 38 - 43.

[18] Adhikari, P. B., Sharma, S. R., \& Baral, K. N. (2016). Features of positive ground flashes observed in Kathmandu Nepal. Journal of Atmospheric and Solar-Terrestrial Physics, 145, 106-113. 